\title{
Chronic Pyelonephritis
}

National Cancer Institute

\section{Source}

National Cancer Institute. Chronic Pyelonephritis. NCI Thesaurus. Code C123216.

Persistent pyelonephritis. 